\title{
Mensurando a violência e o crime: potencialidades, vulnerabilidades e implicações para políticas de segurança pública
}

\section{Luís Felipe Zilli}

Pesquisador em Ciêncio e Tecnologia da Fundação joão Pinheiro (FIP/MG). Dentro da instituição, é vinculado à Diretorio de Políticas Públicas (DPP) e ao Núcleo de Estudos em Segurança Pública (NESP). Possui doutorado e mestrado em Sociologia pela Universidade Federal de Minas Gerais (UFMG) e graduação em Comunicação Social, com habilitaçõo em Jornalismo, pela Pontiffcio Universidade Católica de Minas Gerais (PUC Minas).

Data de recebimento: $23 / 01 / 2018$

Data de aprovação: 17/08/2018

DOI: 10.31060/rbsp.2018.v12.n1.892

\section{Resumo}

A existêncio de dados precisos e confióveis é condição básica para a formulação de políticas públicas. Especialmente na área da Segurança Pública, tal questão adquire centralidade ainda maior, uma vez que, para além das categorios legais empregadas para definir condutos penalizóveis, os próprios instrumentos e meconismos utilizados para produzir informações acabam, em muitos sentidos, determinando visões acerco dos fenômenos criminais e condicionando as respostos que o Estado oferece o eles. Dentro deste contexto, o presente artigo tem como objetivo analisar as principais aplicações e potencialidades, bem como os maiores limites e fragilidades, de três diferentes tipos de fontes de informações costumeiramente utilizadas pela áreo de seguranço pública: (1) registros administrativos e estatísticas oficiais, (2) surveys de vitimizaçõo e (3) pesquisas de outorreportogem. Apresento-se aqui um breve panorama da utilizoção de tais instrumentos no Brasil, bem como uma análise sobre as vantogens e limitoções de tais instrumentos para o produção de conhecimento sobre os fenômenos do violêncio e da criminalidade. De modo geral, observam-se no Brasil três entraves para a produção de conhecimento mais consistente na área da Segurança Pública: (1) a baixa qualidade e confiabilidade dos registros administrativos e das bases de dados oficiais; (2) baixo grau de integração entre os sistemas de informaçõo mantidos pelas organizações que compõem o sistema de justiça criminal; (3) a nõo assimilação, por parte do poder público, de instrumentos alternativos como surveys de vitimização e pesquisas de outorreportagem como mecanismos que possibilitam o controle de qualidade dos dados oficiais e, ao mesmo tempo, servem de insumos para a formulação e a avaliação de políticas públicas. Tais questões nõo apenas prejudicam sensivelmente a compreensõo mais adequada e sofisticada dos problemas de segurança pública que assolam o país, como também fomentam a emergência e a continuidade de políticas públicas reativas, fragmentadas e pouco eficazes na maioria dos estados brasileiros.

\section{Palavras -Chave}

Informação em Seguranço Público; estatísticas criminais; surveys de vitimização; pesquisas de outorreportogem. 


\section{Abstract \\ Measuring violence and crime: potentialities, vulnerabilities and implications for public security policies}

The existence of accurate and reliable data is a basic condition for the formulation of public policies. Especially in the area of public security, this issue takes on greater centrality, since, in addition to the legal categories used to define punishable conduct, the very tools and mechanisms used to produce information determine, in many ways, visions about criminal phenomena and the responses that state offers to them.

In this context, this article aims to analyze the main applications and potentialities, as well as the greater limits and fragilities, of three different types of information sources usually used by public security: (1) official administrative records and criminal statistics, (2) victimization surveys and (3) self-reporting surveys. This article also presents a brief overview about the use of such instruments in Brazil, as well as an analysis of the advantages and limitations of such data for the production of knowledge about the phenomeno of violence and crime.

In general, there are three obstacles in Brozil to produce more consistent knowledge in the areo of Public Security: (1) the low quality and reliability of official records and databases; (2) low integration between the information systems maintained by the criminal justice system; (3) non-assimilation, by public authorities, of alternative instruments such as victimization surveys and self-report surveys (mechanisms that allow the quality control of official dato and, at the some time, serve as inputs for the formulation and evaluation of public policies). Such issues not only undermine the more adequate and sophisticated understanding of public security problems in the country, but also foster the emergence and continuity of reactive, fragmented and ineffective public policies in most Brozilian states.

\section{Keywords}

Public Security Information; Criminal Statistics; Victimization Surveys; Self-report Surveys. 


\section{INTRODUÇÃO}

E

qualquer área de política pública, a existência de dados precisos e confíaveis constitui o insumo mais básico para a ação governamental. $\mathrm{O}$ conhecimento adequado dos problemas sobre os quais se pretende atuar determinará, em muitos sentidos, o grau de eficácia e efetividade das iniciativas estatais. Especificamente na área da Segurança Pública-campo no qual os governos são instados a oferecer soluçóes para problemas relacionados à manutençăo da ordem pública, ao controle e à puniçáo dos delitos e à prevençáo das violências - pensar as questóes da identificaçáo e da mensuraçáo dos fenômenos criminais é central para o ciclo de políticas públicas (SHERMAN et al. 1998; BEATO, 2009; COSTA \& LIMA, 2014).

No Brasil, a despeito da grande melhoria recente dos instrumentos de coleta, sistematizaçáo e análise de dados, diversos fatores continuam se colocando como entraves à consolidaçáo de uma cultura de uso intensivo e sistemático de informaçóes para o planejamento e avaliaçáo das políticas de segurança: questôes que vão desde a precariedade dos registros e bases de dados disponíveis, até as fortes resistências corporativas em romper com culturas institucionais historicamente refratárias à utilizaçáo de modelos técnicos de gestáo. Tal realidade contribui sensivelmente para a formulaçáo de políticas públicas mal focalizadas, parcamente amparadas em evidências empíricas, reativas e pouco articuladas entre si (KAHN, 2000; BEATO FILHO, 2000).

Mesmo em contextos em que já se observam, há alguns anos, políticas e intervençôes sustentadas em uso mais sistemático e intensivo de dados, esse processo ainda se dá quase que exclusivamente por meio da utilizaçáo de registros oficiais de criminalidade. Deixam-se de lado fontes de informaçóes e instrumentos alternativos que, seguramente, poderiam conferir maior precisáo e consistência ao entendimento dos fenômenos criminais (LIMA, 2008).

Buscando contribuir com o debate acerca do uso da informaçáo e de suas tecnologias na área da segurança pública, pretende-se desenvolver neste artigo duas discussóes complementares. A primeira diz respeito às fontes de dados e aos instrumentos disponíveis para mensuraçáo do fenômeno criminal. Propóe-se aqui a análise das características mais gerais, das potencialidades e principais limitaçóes inerentes ao uso de três fontes distintas: (1) registros oficiais de criminalidade, (2) surveys ${ }^{1}$ de vitimizaçáo e (3) pesquisas de autorreportagem. A segunda discussáo 
diz respeito ao atual estágio da utilizaçáo desses instrumentos no Brasil, suas implicaçôes para a compreensáo dos fenômenos de violência e criminalidade e seus impactos para a formulaçáo de políticas públicas de segurança no país.

\section{Fontes de dados e instrumentos de men- suração do crime}

Atualmente, diversos tipos de instrumentos ou fontes de dados se encontram à disposiçấo de gestores públicos ou pesquisadores para mensurar os fenômenos da violência e do crime. Além dos já amplamente difundidos registros administrativos e judiciais (boletins de ocorrência, inquéritos policiais, processos judiciais, cadastros prisionais e socioeducativos, entre outros produzidos pelas organizaçóes do Sistema de Justiça Criminal), também podem ser utilizados dados de pesquisas sociais (como os que sáo produzidos por estudos de vitimizaçáa e de sensaçáo de segurança), registros do Sistema de Saúde (como os dados de mortalidade por causas externas) e mesmo notícias veiculadas por órgãos de imprensa (FIGUEIREDO, 2017).

Este artigo, especificamente, irá se concentrar em discutir questóes referentes a três fontes de informaçáo em Segurança Pública: (1) registros oficiais de criminalidade, (2) surveys de vitimizaçáo e (3) surveys de autorreportagem. Os dois primeiros apresentam informaçóes sobre a epidemiologia do crime: padróes de distribuiçáo espacial, frequências, incidências e prevalências, perfis sociodemográficos e percepçōes das pessoas envolvidas nos fatos. Já o terceiro permite acessar aspectos etiológicos do crime: perfil sociode- mográfico de autores, suas possíveis motivaçóes, variáveis correlatas ou explicaçóes para a prática dos delitos.

\section{Dadose Registros Oficiais de Criminalidade}

Em praticamente todo o mundo, dados oficiais de criminalidade provêm de basicamente três fontes: (1) registros policiais (boletins de ocorrência einquéritos policiais), (2) registros judiciais (denúncias e processos judiciais) e (3) registros de sistemas prisionais ou correcionais (prontuários e relatórios de execuçáo penal). Tratam-se de documentos que trazem informaçóes náo apenas sobre os fatos, os envolvidos e suas condutas em si, mas também sobre a atuação das próprias organizações do Sistema de Justiça Criminal (SJC) dentro do arranjo institucional da segurança pública local (HOWARD, 2000).

Além disso, pesquisadores e gestores também têm a sua disposiçáo dados oriundos dos sistemas de saúde pública, com informaçóes sobre violências contra a pessoa. Geralmente, tratam-se de informaçóes com elevado grau de confiabilidade, fruto de longa tradiçáo de gestáo da informaçáo na área médica. Além de fornecerem dados sobre mortes por causas externas (agressóes e acidentes), os dados da saúde acabam sendo um bom instrumento de controle dos registros produzidos por instituiçóes policiais e judiciais².

\section{Vantagens e potencialidades do uso de dados oficiais}

As maiores vantagens do uso de dados oficiais decorrem de seu elevado grau de institucionalização. Registros administrativos náo apenas

ção de questionários estruturados. No presente artigo, o termo survey será empregado com dois significados: por um lado, em sentido estrito, para designar o método de pesquiso em si; por outro, em sentido mais amplo, para se referir aos dados produzidos por este tipo de pesquisa enquanto fonte de informação para a área de Segurança Pública.

2 No Brasil, a principal fonte de dados sobre óbitos por causas externas é o Sistema de Informações de Mortalidade (SIM), mantido pelo Departamento de Informática do Sistema Único de Saúde (DATASUS) e pelo Centro Nacional de Epidemiologia (CENEPI). Trata-se de base de abrangência nacional e que disponibiliza dados anuais desde 1979. 
adotam procedimentos de definiçáo, coleta e organizaçáo altamente padronizados, como também oferecem longas séries históricas de informaçóes, permitindo análises de trajetória temporal dos fenômenos mensurados. Mesmo em nível internacional, dados oficiais sobre as principais modalidades de crimes possuem definiçóes e formas de registro razoavelmente padronizadas, aspecto que torna possível a realizaçáo de estudos comparativos transnacionais (BENNETT \& LYNCH, 1990).

A análise de dados oficiais também possibilita a melhor compreensão da relaçáo que se estabelece entre "Estado" e "crime/criminoso", uma vez que as informaçóes produzidas pelo SJC constituem o registro mais palpável de como os governos tipificam, processam e reagem aos fenômenos criminais. Tais dados consubstanciam, portanto, discussóes de ordem política e epistemológica sobre processos de construçáo social do crime e mecanismos de incriminaçáo (MISSE, 2008; LIMA, 2005).

Por fim, a grande capilaridade dos sistemas de registros criminais e o desenvolvimento de modernas tecnologias de georreferenciamento de informaçóes fizeram com que fosse possível compreender melhor a relaçáa entre espaço urbano e criminalidade. Tal ferramenta se mostrou fundamental não apenas para o planejamento das atividades de policiamento ostensivo, como também para o gerenciamento das políticas de segurança pública. Através da identificação de hotspots de ocorrências, por exemplo, tornou-se possível acompanhar a evoluçáo espacial e estatística de determinados tipos de crimes, suas possíveis dinâmicas migratórias e relaçóes com espaço urbano, bem como o impacto das intervençōes aplicadas a eles (ANSELIN et al., 2000).

\section{Desvantagens e limitações do uso de da- dos oficiais}

Talvez o maior e mais óbvio problema inerente ao uso de dados oficiais para mensurar os fenômenos da violência e da criminalidade seja seu alto grau de subnotificaçáo, ou as chamadas “cifras ocultas". Já na década de 1960, estudos por amostragem comprovavam que o percentual de crimes que sequer chega ao conhecimento do SJC era bastante expressivo, variando não apenas em funçáo da modalidade e da gravidade dos delitos, mas também em decorrência de questôes mais subjetivas como, por exemplo, os graus de confiança que a populaçáo depositava nos órgáos policiais (LIMA, 2009; ZILLI \& COUTO, 2017).

Todos os países trabalham com taxas de subnotificaçáa para diversas categorias de crimes (CANTOR \& LYNCH, 2000). Na Grá-Bretanha e nos Estados Unidos, por exemplo, estima-se que, de cada 100 crimes cometidos, apenas 50 cheguem ao conhecimento da polícia (BEATO FILHO, 2000). No Brasil, a Pesquisa Nacional de Vitimizaçáo (PNV) realizada em 2012 mostrou que, em média, cerca de $80 \%$ dos crimes ocorridos no país anualmente não chegam ao conhecimento dos órgáos policiais (CRISP/ DATAFOLHA, 2013).

Mesmo para os dados existentes, problemas de articulaçáo entre as diferentes instâncias do SJC também precisam ser levados em conta. No Brasil, crimes registrados pela Polícia Militar (PM), por exemplo, nem sempre se transformam em inquéritos na Polícia Civil (PC). Inquéritos elaborados pela $\mathrm{PC}$, por sua vez, nem sempre são devidamente remetidos ao Ministério Público (MP). Das investigaçôes que chegam ao MP, apenas uma minoria se transforma em denúncia e será encaminhada aos tribunais de justiça para serem julgados. Desses, apenas outra minoriase transformará em pena de condenaçáo e chegará aos sistemas correicionais. Essa "taxa de atrito", com grandes perdas de informaçáo ao 
longo de todas as etapas do fluxo do sistema, prejudica sensivelmente a construçáo de um entendimento mais amplo e consistente dos fenômenos criminais (LEMGRUBER et al., 2002).

Há de se chamar atençáo também para a própria questáo da consistência e confiabilidade dos registros e dados oficiais. Ao longo dos últimos anos, reiterados levantamentos realizados pelo Fórum Brasileiro de Segurança Pública (FBSP) têm demonstrado a existência de problemas consideráveis de precisáo, qualidade e heterogeneidade das informaçóes produzidas pelos estados brasileiros. Em diversas unidades da federação, ainda observa-se inconsistências de coleta, registro e categorizaçáo de dados. Além disso, não raramente, as próprias estruturas das bases de dados encontram-se muito mais voltadas a fornecer insumos para a gestáo das atividades policiais e judiciárias do que para a produçáo de conhecimento e análise de fenômenos criminais (FBSP, 2016). Tudo isso em um contexto organizacional historicamente pouco afeito à adoçáo de práticas de transparência e accountability, aspecto que sistematicamente dificulta o acesso de instituiçóes externas aos dados necessários para a realização de pesquisas e análises mais aprofundadas.

Por fim, também se faz necessário observar uma série de questóes relacionadas aos muitos vieses de seletividade (racial, socioeconômica, geográfica, etária, de gênero, etc.) que caracterizam a atuaçáo cotidiana das organizaçóes policiais e do Sistema de Justiça Criminal no Brasil. Sobretudo na área da Segurança Pública, a atuação estatal sempre se viu historicamente fundada em modelos de vigilância preferencial às classes populares, materializados em éticas e saberes policiais voltados para a criminalizaçáo e incriminaçáo desigual de tipos sociais espećficos (jovens do sexo masculino, negros, pobres, moradores de favelas e bairros pobres de periferia) e ratificados por práticas e mecanismos de seletividade penal (PAIXÃO, 1982; KANT DE LIMA, 1995; RAMOS \& MUSUMECI, 2004; MISSE, 2010, 2014; SINHORETTO et al., 2014).

Tais elementos projetam sobre os registros oficiais fortes vieses de sobrerrepresentaçáo criminal para determinados segmentos e práticas sociais, muitas vezes fazendo com que os dados reflitam muito mais as representaçôes, cogniçôes, modos e direcionamentos de atuaçáo das organizaçóes policiais e do Sistema de Justiça do que propriamente os fenômenos em questáo.

\section{Panorama atual da produção de infor- mações e integração de bases de dados oficiais no Brasil}

Nos últimos anos, o Governo Federal tem operado uma série de tentativas de padronizaçáo e articulaçáo do intrincado mosaico de informaçóes criminais produzidas pelos estados brasileiros. Uma rápida retrospectiva dessas iniciativas ilustra o quão dificil e irregular tem sido esse processo.

A primeira tentativa mais sistemática de produzir bases de dados de abrangência nacional sobre eventos criminais data de 2004, ano de criaçáo do Sistema Nacional de Estatísticas de Segurança Pública e Justiça Criminal (SINESPJC). Trata-se de um sistema que não produz dados próprios, limitando-se a trabalhar na sistematização de registros disponibilizados por organizaçóes de segurança pública de estados e municípios (PM, PC, Corpo de Bombeiros, Guardas Municipais, MP e TJ), organizando uma base de estatísticas criminais em nível nacional (DURANTE \& JÚNIOR, 2012).

Originalmente, o sistema previa a implementação de seis módulos de informaçáo: (1) ocorrências criminais e atividades de segurança pública; (2) perfil das organizaçōes de segurança pública; (3) cadastro nacional de mortes vio- 
lentas; (4) monitoramento da ação policial; (5) fluxo do sistema de justiça criminal; (6) Pesquisa de Vitimização. Destes, no entanto, apenas os módulos de ocorrências criminais e de perfil das organizaçōes de segurança pública foram efetivamente colocados em funcionamento ${ }^{3}$. Ainda assim, diversas avaliações já apontaram problemas consideráveis de consistência e confiabilidade das informaçóes repassadas ao SINESPJC pelos Governos Estaduais (RIBEIRO, 2012).

Entre os anos de 2004 e 2007, o Governo Federal também institucionalizou outros dois sistemas nacionais de informações, igualmente alimentados por informaçóes e registros administrativos disponibilizados por órgáos estaduais: o INFOSEG (Rede de Integração Nacional de Informaçóes de Segurança Pública) e o INFOPEN (Levantamento Nacional de Informaçóes Penitenciárias). O primeiro armazena registros individuais como identificação civil, fichas criminais, dados de veículos, mandados de prisáo, registros de armas de fogo, inquéritos policiais, etc.; já o segundo trabalha com registros de movimentaçôes prisionais, execuçóes penais e cadastros de sentenciados (BATITUCCI, 2007).

Mais de uma década após suas implementaçóes, no entanto, ambos os sistemas ainda enfrentam dificuldades para se consolidarem enquanto instrumentos de melhoria dos níveis de transparência e profissionalizaçáo da gestão dos órgáos de segurança pública. Ainda hoje, as informaçóes produzidas pelo INFOPEN e pelo INFOSEG não sáo sistemática e rotineiramente utilizadas para fins de instrumentalizaçáo de análises criminais e orientaçáo de planejamentos estratégicos (FBSP, 2012).

Prova disso foi a criaçáo, ainda em 2012, também pelo Governo Federal, de um novo sistema modular para servir de repositório nacional de estatísticas de segurança pública. Tratava-se do Sistema Nacional de Informaçöes de Segurança Pública, Prisionais e sobre Drogas (SINESP)4, portal que, no médio prazo, tinha como objetivo substituir os sistemas anteriores e congregar, para todos os estados, dados sobre os seguintes quesitos:

1) Ocorrências criminais registradas e respectivas comunicaçóes legais;

2) Registros de armas de fogo;

3) Entrada e saída de estrangeiros;

4) Pessoas desaparecidas;

5) Execuçăo penal e sistema prisional (organizando dados produzidos pelo SisDepen, sistema que, desde fevereiro de 2017, substituiu o INFOPEN);

๑) Recursos humanos e materiais dos órgáos e entidades de Segurança Pública;

7) Condenaçóes, penas, mandados de prisão e contramandados de prisão;

8) Repressão à produçăo, fabricaçăo e tráfico de crack e outras drogas ilíitas e a crimes conexos, bem como apreensáo de drogas lícitas;

9) Taxas de elucidação de crimes.

O capítulo mais recente da série de iniciativas federais para tentar consolidar bases de dados e sistemas de informaçáo de abrangência nacional para a área de Segurança Pública se deu em junho de 2018, com a aprovaçáo da Lei 13.675. O dispositivo legal instituiu a criaçáo do Sistema Único de Segurança Pública (SUSP) e, dentro dele, um grande módulo informacional chamado de "Sistema Nacional de Informaçóes e de Gestáo de Segurança Pública e Defesa Social". Tal módulo, por sua vez, prevê a criaçáo de um submódulo chamado de "Sistema Nacional de Informaçôes de Segurança Pública, Prisionais e 
de Rastreabilidade de Armas e Muniçóes, e sobre Material Genético, Digitais e Drogas" (SI$\mathrm{NESP}$ ), que terá como função

armazenar, tratar e integrar dados e informaçóes para auxiliar na formulaçáo, implementaçáo, execuçáo, acompanhamento e avaliaçáo das políticas relacionadas com segurança pública e defesa social, sistema prisional e execução penal, rastreabilidade de armas e muniçóes, banco de dados de perfil genético e digitais e enfrentamento do tráfico de drogas ilícitas (BRASIL, 2018).

Sob a lógica de condicionar o repasse de reaursos federais ao fornecimento de dados criminais razoavelmente padronizados por parte dos estados, a lei do SUSP estabelece:

\section{Art. 36. O Sinesp tem por objetivos:}

I - procederà coleta, análise, atualizaçáo, sistematizaçăo, integraçăo e interpretaçăo de dados e informaçóes relativos às políticas de segurança pública e defesa social;

II - disponibilizar estudos, estatísticas, indicadores e outras informaçóes para auxiliar na formulaçáo, implementação, execuçāo, monitoramento e avaliaçáo de políticas públicas;

III - promover a integração das redes e sistemas de dados e informaçōes de segurança pública e defesa social, criminais, do sistema prisional e sobre drogas;

IV - garantir a interoperabilidade dos sistemas de dados einformaçōes, conforme os padrōes definidos pelo conselho gestor. (BRASIL, 2018).

Por fim, outro esforço de consolidaçáo de dados e de promoçáo da transparência das informaçôes sobre crime e violência no país é feito pelo Fórum Brasileiro de Segurança Pública (FBSP), entidade da sociedade civil que produz os Anuários Brasileiros de Segunança Pública. Publicados desde 2007, os documentos trazem não apenas estatísticas consolidadas sobre ocorrências criminais em todo o país (obtidas por meio do sistema SINESPJC e também via consulta direta aos estados), mas também dados primários produzidos via pesquisas próprias e informaçóes sobre as instituiçóes que formam o campo organizacional de segurança pública no Brasil (FBSP, 2017).

A despeito de todos estes esforços, o que se observa é que, para além das questôes de precisão e confiabilidade dos registros, ainda perdura um quadro de grande fragmentaçáo e desarticulaçáo dos dados oficiais no Brasil. Tal cenário, por sua vez, impóe entraves à compreensáo mais estruturada dos problemas de violência e criminalidade em âmbito nacional.

\section{Surveys de Vitimização}

Como alternativa e complementaçáo aos registros oficiais, os surveys de vitimização vêm se constituindo, ao longo dos últimos 60 anos, em um dos melhores instrumentos de mensuraçáo e de compreensáo da etiologia do fenômeno criminal. Por meio da aplicação de questionários em amostras representativas de determinadas populaçôes, pesquisas de vitimização podem obter dados detalhados não apenas sobre a quantidade, mas também sobre as principais características dos crimes sofridos pelos entrevistados. Permitem mensurar, inclusive, o volume aproximado de delitos que não chegaram ao conhecimento da polícia (as chamadas "cifras ocultas").

Pode-se dizer que os principais objetivos dos surveys de vitimizaçáo são:

Estimar a quantidade de delitos e conflitos ocorridos no período de referência, registrados ou não pela polícia; estimar as taxas de notificação à polícia para cada categoria de crimes; conhecer os motivos da subnotificaçáo, para cada categoria de crimes; conhecer as circunstâncias em que ocorrem os diversos tipos de delitos (locais, horários 
etc.); conhecer detalhadamente as características das vítimas (sexo, idade, raça, renda, escolaridade, hábitos, estilos de vida etc.), permitindo a definiçáo dos grupos de risco para cada categoria de crimes; conhecer as características dos/as agressores/as identificados/as pelas vítimas e especificar, para os vários tipos de crimes, a relaçáo existente entre vítima e agressor/a (familiar, conhecido, desconhecido etc.); conhecer as percepçóes de insegurança e o grau de confiança da populaçáo nas agências do sistema de justiça criminal; conhecer as medidas preventivas utilizadas pelas vítimas reais ou potenciais, as providências tomadas após a vitimização e os mecanismos endógenos (informais ou náo-oficiais) de resoluçáo de conflitos. (LEMGRUBER et al, 2002)

\section{Vantagens e potencialidades do uso de surveys de vitimização}

Surveys de vitimizaçáo sáo instrumentos elaborados não apenas para a mensuraçáo das experiências de vitimização criminal, mas, sobretudo, para a melhor compreensáo de aspectos ligados à distribuiçáo espacial, frequência, incidência, perfil das vítimas, rotinas e práticas que possivelmente se encontram correlacionadas a maiores taxas de vitimizaçáo.

Outra vantagem associada à metodologia utilizada pelos surveys de vitimizaçáo é a possibilidade de conhecer melhor diferentes aspectos de crimes de natureza sexual, ou outras violências praticadas em ambientes privados ou familiares. O caráter de anonimato e impessoalidade dos questionários possibilita às vítimas relatar suas experiências e contribuir para o aumento do conhecimento sobre esse tipo de crime.
Além disso, como os surveys trabalham com um corpo metodológico já bastante consolidado em todo o mundo, cria-se a possibilidade de realizar estudos comparativos entre diferentes cidades, regióes e países. Entre os exemplos de surveys de vitimizaçáo já amplamente consolidados podem ser elencados o International Crime Victims Survey (ICVS), levantamento realizado por um consórcio de pesquisadores ligados ao UNICRI das Naçóes Unidas's, e o norte-americano National Crime Victimization Survey (NCVS), levantamento realizado anualmente, desde 1973, pelo Governo dos Estados Unidos em todo seu território. Este último cobre, hoje, uma amostragem de aproximadamente 135 mil domicilios, com cerca de 225 mil entrevistados ${ }^{6}$.

\section{Desvantagens e limitações do uso de surveys de vitimização}

Apesar de todas as potencialidades mencionadas anteriormente, pesquisas de vitimizaçáo implicam em altos custos financeiros para realizaçáo, o que frequentemente obriga instituiçóes de pesquisa a trabalhar com amostras menores, com abrangência mais restrita e periodicidade mais estendida. Salvo raras exceçóes, dados de vitimizaçáo frequentemente dizem respeito a poucas cidades ou regióes metropolitanas e, ainda assim, com longos intervalos de tempo entre uma rodada e outra.

Tais intervalos podem acarretar prejuízos para a mensuraçáo do fenômeno criminoso, uma vez que o survey é um instrumento que trabalha fundamentalmente apoiado na memória de seus entrevistados. Dependendo do período pregresso que o survey pretende abranger, o rela-

5 Até agora, cinco rodadas já foram realizadas, nos anos de 1989, 1992, 1996, 2000 e 2004, abrangendo aproximadamente 50 países. o Brasil participou das três últimas rodadas, através de questionários aplicados nas cidades de Rio de Janeiro e São Paulo. 6 Atualmente, juntamente com os ocorrências e registros policiais, o NCVS é tomado como instrumento de mensuração oficial do criminalidade nos EUA (LEMGRUBER et al., 2002). 
to das experiências de vitimizaçáo pode ser prejudicado. Além disso, aspectos cognitivos inerentes à própria metodologia de survey também interferem na possibilidade de comparar dados obtidos por diferentes pesquisas de vitimizaçáo e até mesmo por diferentes rodadas de uma mesma pesquisa. A forma como as questóes sáo colocadas e mudanças na formulaçáo de algumas questóes entre uma rodada e outra podem modificar os resultados obtidos e invalidar ou prejudicar a medição.

Outro aspecto que precisa ser levado em conta é o escopo das pesquisas. Surveys de vitimizaçáo medem, fundamentalmente, crimes nos quais os entrevistados figuram como vítimas. Ficam de fora, portanto, práticas como uso de drogas, porte e posse ilegal de armas, prostituiçáo e tantos outros que podem socialmente fazer parte da rotina dos próprios entrevistados, mas que eventualmente podem compor o espectro de práticas e comportamentos ocasionalmente tipificados como crime (MOSHER et al., 2002).

Além disso, por se tratar de um instrumento que pretende medir fundamentalmente a vitimizaçáo criminal, os surveys acabam não proporcionando muitas informaçóes sobre o perfil dos agressores. As únicas informaçóes sobre os autores de crimes se dáo pela via indireta da memória das vítimas.

\section{Panorama atual das pesquisas de vitimi- zação no Brasil}

No Brasil, as pesquisas de vitimização vêm se consolidando, mas ainda sáo um instrumento utilizado de maneira pouco sistemática. $\mathrm{O}$ primeiro levantamento no país se deu em 1988, através de um suplemento da Pesquisa Nacional por Amostra de Domicilios (PNAD), realizada pelo IBGE. Depois dela, pelo menos outras 46 pesquisas de vitimização foram realizadas em diferentes cidades brasileiras até $o$ ano de 2017. No entanto, a falta de padronizaçáo metodológica torna dificil a realizaçáo de estudos comparativos. O Quadro 1 apresenta um panorama das pesquisas de vitimizaçáo já realizadas no Brasil.

Até hoje, apenas uma pesquisa de vitimização de abrangência efetivamente nacional foi realizada no Brasil. A Pesquisa Nacional de Vitimizaçáo (PNV), cujo campo foi realizado entre 2010 e 2012, foi financiado pelo Ministério da Justiça (MJ) e contou com uma amostra representativa da populaçáo brasileira, com idade igual ou superior a 16 anos, moradora de cidades com mais de 15 mil habitantes. O survey, conduzido pelo Centro de Estudos de Criminalidade e Segurança Pública da Universidade Federal de Minas Gerais (CRISP/UFMG), em parceria com o Instituto de Pesquisas Datafolha, foi feito em 346 municípios de todos os estados da federaçáo, formando uma base de dados composta por 78.008 questionários ${ }^{7}$.

Tratou-se do primeiro esforço de âmbito nacional que, usando metodologia e questóes semelhantes aos surveys do UNICRI, dedicou-se não apenas a mensurar os reais índices de vitimizaçáo criminal da populaçáo brasileira, mas também as percepçóes públicas sobre questôes como sensaçáa de segurança, confiança nas organizaçóes policiais e a avaliaçáo da qualidade da atuação das instituiçóes do SJC (CRISP, 2013). 


\begin{tabular}{|c|c|c|c|c|}
\hline Pequisa & Ano & Abrangência & Categoria & Amostra \\
\hline Pnad & 1988 & Brasil & 1 ano & 81.628 domicílios \\
\hline \multirow{3}{*}{ Ilanud } & 1992 & \multirow{3}{*}{$\begin{array}{l}\text { Município do Rio de Janeiro } \\
\text { e Município de São Paulo }\end{array}$} & 5 anos & 1.000 entrevistados \\
\hline & 1996 & & 5 anos & 1.000 entrevistados \\
\hline & 1997 & & 5 anos & 2.400 entrevistados \\
\hline ISER/PAHO & 1996 & Município do Rio de Janeiro & 5 anos & 2.469 entrevistados \\
\hline ISER/FGV & 1996 & RMRJ - RJ & 1 ano & 1.126 entrevistados \\
\hline $\begin{array}{c}\text { 0 Povo e a } \\
\text { Polícia Militar }\end{array}$ & $1997 / 98$ & Distrito Federal & Toda a vida & 2.000 entrevistados \\
\hline SEADE & 1998 & $\begin{array}{l}\text { RMSP - SP e municípios com } \\
\text { mais de } 50 \text { mil habitantes }\end{array}$ & 1 ano & 14.000 domicílios \\
\hline USP & 1999 & RMSP & 6 meses & 1.000 entrevistados \\
\hline ISER & 2000 & Baixada Fluminesne - RJ & 1 ano & 1.389 entrevistados \\
\hline CDHP - IBGE & 2001 & Copacabana e Leme & 1 ano & 450 entrevistados \\
\hline $\begin{array}{l}\text { Univ. de Caxias } \\
\text { do Sul }\end{array}$ & 2001 & Caxias do Sul (RS) & $\begin{array}{c}\text { Sem } \\
\text { Informações }\end{array}$ & sem informação \\
\hline $\begin{array}{l}\text { Módulo da PESB } / \\
\text { DATAUFF }\end{array}$ & 2002 & Brasil & Toda a vida & $\begin{array}{l}2.460 \\
\text { entrevistados }\end{array}$ \\
\hline Ilanud/FIA/USP & 2002 & $\begin{array}{l}\text { São Paulo, Rio de Janeiro, } \\
\text { Vitória e Recife (municípios) }\end{array}$ & 5 anos & $\begin{array}{l}2.800 \\
\text { entrevistados }\end{array}$ \\
\hline ISP/Viva Rio & 2002 & Município do Rio de Janeiro & 1 ano & 765 entrevistados \\
\hline CRISP & 2002 & Município de Belo Horizonte & 1 e 5 ano(s) & 4.000 entrevistados \\
\hline Inst. Futuro Bras. & 2003 & Município de São Paulo & 1 e 5 ano(s) & 5.000 domicílios \\
\hline GUTO - UNESP & 2003 & Município de Marília - SP & Toda a vida & não consta \\
\hline $\begin{array}{l}\text { Módulo do BH } \\
\text { Área Survey }\end{array}$ & 2003 & Município de Belo Horizonte & 1 ano & 1.029 entrevistados \\
\hline CPP/INSPER & 2003 & Município de São Paulo & 1 ano & 5.000 entrevistados \\
\hline Prefeitura & 2004 & Alvorada (RS) & 1 ano & 500 domicílios \\
\hline IBPS - PM & 2005 & Rio de Janeiro & 1 mês & $\begin{array}{l}1.100 \text { entrevistados } \\
\text { por telefone }\end{array}$ \\
\hline CRISP/SSP & 2005 & Curitiba & 1 e 5 ano(s) & 3.560 entrevistados \\
\hline NEPP - PR & 2005 & Foz do Iguaçú & sem informação & 700 entrevistados \\
\hline $\begin{array}{l}\text { SENASP - SEGUP - } \\
\text { UFPA/CCS }\end{array}$ & 2005 & $\begin{array}{l}\text { RM de Belém - PA e } \\
8 \text { municípios do interior }\end{array}$ & 2 anos & 2.848 entrevistados \\
\hline NUPEVI/UERJ & $2005 / 06$ & Município do Rio de Janeiro & $\begin{array}{l}\text { Toda a vida } \\
\text { e } 1 \text { ano }\end{array}$ & 4.000 entrevistados \\
\hline
\end{tabular}




\begin{tabular}{|c|c|c|c|c|}
\hline CRISP & 2006 & RMBH - MG & 1 e 5 ano(s) & 6.220 entrevistados \\
\hline $\begin{array}{c}\text { SEADE/Bloco } \\
\text { da PED }\end{array}$ & 2006 & RMSP - SP & sem informação & 3.000 domicílios/mês \\
\hline ISP & 2007 & RMRJ - RJ & 1 e 5 ano(s) & 5.000 entrevistados \\
\hline CRISP & 2007 & Município de Itabira - MG & 1 e 5 ano(s) & 401 entrevistados \\
\hline Prefeitura & 2007 & Esteio/RS & 23 meses & 2.682 entrevistados \\
\hline $\begin{array}{l}\text { Univ. Fed. } \\
\text { de Pelotas }\end{array}$ & $2007 / 08$ & Município de Pelotas - RS & 1 e 5 ano(s) & 2.918 entrevistados \\
\hline $\begin{array}{c}\text { Instituto } \\
\text { Futuro Brasil }\end{array}$ & 2008 & RMSP - SP & 1 e 5 ano(s) & 3.000 domicílios \\
\hline UFGO & 2008 & RM Gioânia - G0 & sem informação & 3.200 entrevistados \\
\hline $\begin{array}{l}\text { Inst. Maurício } \\
\text { de Nassau }\end{array}$ & 2008 & Recife - PE & Toda a vida & 795 entrevistados \\
\hline $\begin{array}{c}\text { Consórcio } \\
\text { Intermunicipal } \\
\text { Grande Vitória }\end{array}$ & 2008 & Região Grande Vitória ES & 1 e 5 ano(s) & 5.001 entrevistados \\
\hline $\begin{array}{l}\text { Inst. Maurício } \\
\text { de Nassau }\end{array}$ & 2008 & Recife - PE & 5 anos & 795 entrevistados \\
\hline SSP/Prefeitura & 2009 & Canoas - RS & 1 ano & 1.500 domicílios \\
\hline CPP/INSPER & 2009 & Município de São Paulo & 1 ano & 2.967 entrevistados \\
\hline UNESP & 2010 & Município de Pompéia - SP & sem informação & 84 entrevistados \\
\hline IUPERJ/IBOPE & 2010 & Brasil & 1 e 5 ano(s) & 3.612 entrevistados \\
\hline CRISP & $2010 / 11$ & Município de Contagem - MG & 1 e 5 ano(s) & 352 entrevistados \\
\hline UFV & 2012 & Município de Viçosa - MG & sem informação & sem informação \\
\hline CRISP/DATAFOLHA & 2012 & Brasil & $\begin{array}{l}\text { Toda a vida } \\
\text { e } 1 \text { ano }\end{array}$ & 78.000 entrevistados \\
\hline CPP/INSPER & 2013 & Município de São Paulo & 1 ano & 3.000 entrevistados \\
\hline FBSP/SENASP - MJ & 2015 & Brasil & Toda a vida & $\begin{array}{c}10.323 \text { entrevistados } \\
\text { (agentes de Seg. } \\
\text { Pública) }\end{array}$ \\
\hline FBSP/DATAFOLHA & 2017 & Brasil & 1 e 10 anos & 2.073 entrevistados \\
\hline
\end{tabular}

Fonte: Zilli, Marinho e Silva, 2014. (Atualizado para a confecção deste artigo)

\section{Surveys de autorreportagem}

Assim como os surveys de vitimizaçáo, as pesquisas de autorreportagem (self-report surveys) sáo uma alternativa complementar às fontes de dados oficiais. No entanto, eles não têm como foco as vítimas, mas sim os autores da açáo criminal: buscam, através da aplicaçáo de ques- tionários junto a amostras representativas de determinadas populaçóes, mensurar a distribuiçấo de práticas delituosas pela sociedade, perguntado aos entrevistados sobre os delitos praticados por eles mesmos. 
O primeiro registro que se tem desse tipo de pesquisa data de 1946, no estado do Texas, Estados Unidos. $\mathrm{Na}$ ocasião, foram analisados registros criminais de 2.049 jovens, identificando-se 55 delitos pelos quais eles haviam sido responsabilizados criminalmente. Em seguida, os pesquisadores submeteram 337 estudantes universitários (200 homens e 137 mulheres) a questionários, nos quais perguntavam se eles já haviam praticado (e com qual frequência) algum destes delitos. Ao final da pesquisa, constatou-se que todos os universitários já haviam cometido pelo menos um dos crimes em questáo, ainda que com uma frequência menor àquela observada entre os jovens responsabilizados judicialmente (THORNBERRY \& KROHN, 2000).

Desde a década de 1960, as pesquisas de autorreportagem se tornaram um importante instrumento de mensuraçáo do fenômeno do crime, sobretudo em países como Estados Unidos, Austrália e Inglaterra. Entre as pesquisas de maior porte, podem ser citadas o National Youth Survey (realizado desde 1976) e o Monitoring the Future (desde 1975), levantamentos realizados anualmente nos $\mathrm{EUA}^{8}$ e que acompanham amostras de jovens ao longo de vários anos (JOHNSTON et al., 1996).

Atualmente, um dos projetos mais ambiciosos de pesquisa de autorreportagem é o International Self-Report Delinquency (ISRD). Até 2017, três rodadas dessa pesquisa já haviam sido aplicadas, usando questionários padronizados: 1992/1993 com 13 países; 2005/2007 com 31 países; e 2012/2019 com 34 países (HOWARD et al., 2000).

\section{Vantagens e potencialidades do uso de surveys de autorreportagem}

Pesquisas de autorreportagem têm como principal objetivo o preenchimento de uma importante lacuna existente na compreensáo do fenômeno criminal: a etiologia do crime e do criminoso. É um instrumento que possibilita não apenas construir um quadro mais aproximado da real distribuiçáo das práticas delituosas pelos diferentes estratos da sociedade, mas também traçar um perfil mais realista sobre a evoluçáo das "carreiras criminosas" identificadas.

Surveys de autorreportagem também ajudam a compreender melhor causas, motivações e possíveis constrangimentos inerentes à prática de delitos. Por se tratar de um instrumento abrangente, os questionários acabam produzindo informaçōes sobre os principais elementos motivadores da açáo criminal, bem como de fatores que possivelmente poderiam inibir a prática delinquente. Nesse sentido, os self-report surveys constituem instrumento valioso para o desenvolvimento e a implementaçáo de políticas públicas de segurança.

Foi por meio de pesquisas de autorreportagem que pesquisadores como Clark e Wenninger (1962), EmpeyeErickson (1966), Dunaway e colegas (2000), por exemplo, encontraram pouca correlaçáo entre status socioeconômico ea prática de crimes, chegando quase a afirmar quea prática de atos delinquentes se encontrava distribuída de maneira relativamente homogênea por todas as classes, resguardadas algumas diferenças relativas ao perfil da delinquência cometida.

8 Outro survey de outorreportagem bastante tradicional utilizado nos Estados Unidos é o National Household Survey on Drug Abuse, instrumento que oferece a pesquisadores e gestores públicos um painel significativo do uso de drogas no país. (MOSHER et al, 2002). 
Dentler e Monroe (1961) e Elliott e Ageton (1980) por sua vez, encontraram correlaçóes significativas entre a prática de roubo e variáveis como idade, sexo e gênero. Outros estudos fizeram uso de pesquisas de autorreportagem para avaliar correlatos menos controversos como, por exemplo, a influência de pares no comportamento delinquente, dimensão importante para a compreensáo de crimes ligados a gangues e grupos armados, por exemplo (THORNBERRY $\& \mathrm{KROHN}, 2000)$.

\section{Desvantagens e limitações do uso de pesquisas de autorreportagem}

Pesquisas de autorreportagem possuem limitaçóes inerentes à própria metodologia dos surveys: costumam mobilizar grandes equipes de pesquisadores e analistas, o que torna sua realização bastante onerosa. A questão dos custos, por sua vez, projeta reflexos sobre o tamanho da amostra e sobre a periodicidade entre a realizaçáo de diferentes rodadas. Consequentemente, isso pode trazer prejuízos para a representatividade da amostra e a capacidade de generalização das condusóes oferecidas pelos dados da pesquisa.

Além disso, diferentes desenhos de pesquisa (entre levantamentos distintos, ou até mesmo entre diferentes rodadas de uma mesma pesquisa) são capazes de alterar significativamente os resultados obtidos: a forma de colocaçáo e a própria ordem em que as perguntas sáo apresentadas aos entrevistados podem modificar sensivelmente o conteúdo e a sinceridade das respostas (MOSHER et al., 2002).

Outra questáo bastante discutida no que se refere aos surveys de autorreportagem seria uma possível tendência dos entrevistados a sub-repre- sentar sua participaçáo em crimes mais graves. Essa questáo também foi debatida em estudo conduzido por Elliott e Ageton (1980) que chegaram à conclusáo de que, ao contrário do que se poderia imaginar, os self-report surveys constituem, sim, um instrumento estatisticamente válido para medir comportamento delinquente de maior potencial ofensivo. Os autores argumentam que a prova dessa validade pode ser encontrada na diferença relativamente pequena que existe entre os resultados obtidos pelos registros oficiais de crimes sérios e os dados obtidos pelos surveys de autorreportagem para esses tipos de delitos.

A maior parte da diferença entre os dados oficiais e aqueles obtidos pelos self-report surveys se devem ao fato de estes serem um instrumento mais eficiente de mensuraçáo de pequenos delitos do que os registros oficiais, uma vez que as organizaçóes policiais têm praticamente toda a sua estratégia de atuaçáo voltada para o enfrentamento de delitos mais graves (ELLIOTT \& AGETON, 1980).

\section{Panorama atual dos surveys de autorre- portagem no Brasil}

Surveys de autorreportagem ainda constituem um instrumento pouquíssimo utilizado no Brasil. Seu uso ainda se encontra praticamente restrito à investigaçáo do tema da violência nas escolas e, mesmo assim, a autorreportagem de atos delinquentes em si se dá em pequenas partes dos questionários. O que se tem, na maioria das vezes, sáo instrumentos mistos que agregam pesquisas de vitimizaçáa, percepçáo de violência e autorreportagem em um único levantamento. 
Três pesquisas nesses moldes já foram conduzidas pelo CRISP/UFMG . A primeira, feita em 2002, teve uma amostra de 2.600 estudantes de 50 escolas públicas e privadas de Belo Horizonte. A segunda aconteceu em 2005, com amostra de 3.600 alunos de 65 escolas públicas e privadas da Regiáo Metropolitana de Belo Horizonte (RMBH). A terceira pesquisa foi realizada um ano depois, abrangendo 1.900 estudantes de 37 escolas públicas de $\mathrm{BH}$. Nos questionários aplicados, o envolvimento dos estudantes em comportamentos delinquentes foi medido a partir de perguntas como:

- Alguma vez, vocêjá agrediu algum (a) professor (a) com palavras (xingamentos, palavróes, etc.), nessa escola?

- Você já trouxe, ou tentou trazer, alguma arma de fogo (como revólver, pistola e outros) para a escola?

- Você já trouxe, ou tentou trazer, alguma arma branca (como faca, canivete, navalha, porrete etc.) para a escola?

- Você pertence a alguma gangue?

- Você já se envolveu em alguma briga de gangue?

Além dos levantamentos realizados pelo CRISP, outra pesquisa de autorreportagem foi conduzida em São Paulo pelo ILANUD e pelo Instituto Sou da Paz, em 1999, com amostra de 1.000 alunos de 40 escolas públicas e particulares. Para o levantamento, 2\% dos alunos afirmaram já ter trazido uma arma de fogo para a escola, enquanto 9,3\% assumiram já ter praticado furtos de pequeno valor (ILANUD, 1999).
Em 2001, o próprio ILANUD realizou outro levantamento de autorreportagem em São Paulo, junto a uma amostra de 2.100 adolescentes com passagens pela antiga Fundaçáo Estadual para o Bem Estar do Menor (FEBEM). A principal intençáo da pesquisa era comparar os registros criminais oficiais mantidos para estes jovens e os delitos autorreportados por eles. Além disso, o levantamento também pretendia analisar questóes referentes a uso de drogas e status socioeconômico (ILANUD, 2002).

Outro exemplo de pesquisa mista foi a "Caminhada de crianças, adolescentes e jovens na rede do tráfico de drogas no varejo do Rio de Janeiro, 2004-2006", realizada pelo Observatório de Favelas do Rio de Janeiro, pela UNICEF e pela Organizaçáo Internacional do Trabalho (OIT), com amostra de 230 jovens envolvidos com tráfico de drogas em 34 favelas da capital carioca. Para a pesquisa, 65,2\% dos jovens admitiu ter entrado para o tráfico antes dos 15 anos de idade. Outros $25,7 \%$ correlacionaram sua adesão às quadrilhas a questôes como "sensação de poder", "vontade de usar uma arma”, "adrenalina”, "prestígio", etc. (OBSERVATÓRIO DE FAVELAS, 2006).

O que se observa, portanto, é uma utilização ainda bastante tímida da metodologia de autorreportagem no Brasil, ainda assim por meio de instrumentos mistos que agregam, sob o mesmo questionário, questóes de vitimizaçáo, percepçáo de violência e delinquência autoassumida.

\section{Considerações Finais}

Partindo do pressuposto de que a existência

9 A pesquiso sobre violêncio nas escolas de 2005, por exemplo, detectou forte correlação entre a variável "pertencimento a gangues" e maiores níveis de envolvimento dos jovens com outros violêncios e próticas criminosos (CRISP, 2005). 
de dados precisos e confiáveis é condiçáo fundamental para a produçáo de políticas de segurança pública, o presente artigo procurou analisar as potencialidades e limites de três instrumentos costumeiramente utilizados para dimensionar os fenômenos criminais: (1) registros e dados oficiais, (2) surveys de vitimizaçáo e (3) pesquisas de autorreportagem. Nesse sentido, procurou-se não apenas problematizar as principais características e usos destas três fontes de informaçáo, mas também discutir suas implicaçóes para a compreensáo mais adequada dos fenômenos criminais e para o desenvolvimento de políticas de segurança pública no Brasil.

Em termos estruturais, três ordens de problemas podem ser identificadas como entraves para a produçáo de conhecimento mais consistente e qualificado na área da segurança pública no Brasil. A primeira relaciona-se ao histórico de baixos níveis de qualidade e de confiabilidade dos registros administrativos e bases de dados oficiais sobre criminalidade no país. Tal passivo é tributário não apenas do tempo relativamente curto desde que as organizaçóes policiais e demais órgáos do SJC passaram a trabalhar com bases de dados e sistemas de análise criminal mais estruturados, mas também do fato de que tal incorporaçáo se deu em um campo organizacional e corporativo historicamente refratário ao uso de tecnologias e metodologias mais sofisticadas de gestáo da informaçáo (sobretudo porque tal uso induz, qua- se que necessariamente, aumento dos níveis de transparência e accountability).

A segunda ordem de questôes também diz respeito aos registros oficiais: a forte fragmentaçáo organizacional que caracteriza arranjo de segurança pública no Brasil reflete-se nos baixos níveis de articulaçáo entre as bases de dados e sistemas de registro do SJC. Mesmo entre as policias, as bases de dados frequentemente não dialogam entre si, prestando-se mais a instrumentalizar a gestáo interna de cada organização do que propriamente produzir conhecimento integrado sobre os fenômenos criminais. O paroxismo desta desarticulaçáa pode ser visto na impossibilidade de se reconstituir, de maneira automatizada, o fluxo completo de uma ocorrência criminal, desde seu registro policial inicial, até seu processamento final por parte do poder judiciário.

Por fim, também constitui entrave à produção de informaçóes qualificadas a não assimilaçáo, por parte de gestores públicos e policy makers, de instrumentos alternativos como surveys de vitimizaçáo e de autorreportagem. O uso sistemático de tais instrumentos possibilitaria ao poder público não apenas sofisticar suas compreensóes sobre a etiologia e a epidemiologia dos fenômenos criminais, mas, fundamentalmente, orientar melhor todos seus ciclos de políticas públicas.

\section{Referências Bibliográficas}

ANSELIN, Luc et al. Spatial Analysis of Crime. Criminal Justice, vol. 4, n. 2, 2000, p. 213-262.

BATITUCCI, Eduardo Cerqueira. As limitações da contabilidade oficial de crimes no Brasil: o papel das instituições de pesquisa e estatística. São Paulo em Perspectiva, vol. 21, n. 1, 2007, p. 7-18. 
BEATO, Cláudio. Fontes de dados policiais em estudos criminológicos: limites e potenciais. Fórum de debates IPEA, 2000.

BEATO, Cláudio. Gestão da Informação. In: SECRETARIA NACIONAL DE SEGURANÇA PÚBLICA, Coleção Segurança com Cidadania: sistemas de informação, estatísticas criminais e cartografias sociais. Brasilia, 2009.

BENNEIT, Richard R.; LYNCH, James P. Does a difference make a difference? Comparing cross-national crime indicators. Criminology, v. 28, n. 1, 1990, p. 153-181.

BRASIL. Lei 13.675, de 18 de junho de 2018. Disciplina a organização e o funcionamento dos órgãos responsáveis pela segurança pública, nos termos do $§ 7^{\circ}$ do art. 144 da Constituição Federal; cria a Política Nacional de Segurança Pública e Defesa Social (PNSPDS); institui 0 Sistema Único de Segurança Pública (Susp). Brasília, DF, jun 2018.

CANTOR, David; LYNCH, James P. Self-report surveys as measures of crime and criminal victimization. Criminal Justice, v. 4, п. 1, 2000, p. 85-138.

CLARK, John.; WENNINGER, E.P. Socioeconomic class and area as correlates of illegal behavior among juveniles. American Sociological Review, v. 27, n. 6, 1962, p. 826-834.

COSTA, Arthur Trindade; LIMA, Renato Sérgio. Segurança Pública. In: LIMA, Renato Sérgio; RATTON, José Luiz; AZEVEDO, Rodrigo Ghiringhelli. Crime, Polícia e Justiça no Brasil. São Paulo: Editora Contexto, 2014.

CRISP. Pesquisa sobre Violência nas Escolas: relatório técnico final. Belo Horizonte: Universidade Federal de Minas Gerais (UFMG), 2005.

CRISP; DATAFOLHA. Pesquisa Nacional de Vitimização - Relatório Técnico. Belo Horizonte: Universidade Federal de Minas Gerais (UFMG), 2013.
DENTLER, Robert A.; MONROE, Lawrence J. Social correlates of early adolescent theft. American Sociological Review, 1961, p. 733-743.

DUNAWAY, Gregory R.; CULLEN, Francis T.; BURTON Velmer S.; EVANS, T. David. The Myth of Social Class and Crime Revisited: an examination of class and adult criminality. Criminology, v. 38, n. 2, 2000, p. 589-632.

DURANTE, Marcelo Ottoni; JÚNIOR, Almir de Oliveira. A produção de estatísitcas e indicadores de seguranca pública no Brasil em perspectiva histórica e a criação do Sistema Nacional de Estatísticas de Segurança Pública e Justiça Criminal (SINESPIC). In: FÓRUM BRASILEIRO DE SEGURANÇA PÚBLICA. $6^{\circ}$ Anuário Brasileiro de Segurança Pública. São Paulo. 2012.

ELLIOT, Delbert S.; AGETON, Suzanne S. Reconciling race and class differences in self-reported and official estimates of delinquency. American Sociological Review, 1980, p. $95-110$.

EMPEY, Lamar T.; ERICKSON, Maynard. Hidden delinquency and social status. Social Forces, v. 44, n. 4, 1966, p. 546-554.

FIGUEIREDO, Isabel A Gestão de informações e o papel da SENASP. Boletim de Análise Político-Institucional, ก. 11, 2017.

FÓRUM BRASILEIRO DE SEGURANÇA PÚBLICA (FBSP). Anuário Brasileiro de Segurança Pública 2012. São Paulo. 2012.

FÓRUM BRASILEIRO DE SEGURANÇA PÚBLICA (FBSP). Anuário Brasileiro de Segurança Pública 2016. São Paulo. 2016.

FÓRUM BRASILEIRO DE SEGURANÇA PÚBLICA (FBSP). Anuário Brasileiro de Segurança Pública 2017. São Paulo. 2017. 
HOWARD, Gregory J., NEWMAN, Graeme, PRIDEMORE, William Alex. Theory, Method and Data in Comparative Criminology. Criminal Justice, v. 4, n. 4, 2000, p. 139211.

ILANUD; INSTITUTO SOU DA PAZ 0 dia a dia na vida das escolas: violências autoassumidas. São Paulo, 1999.

ILANUD. Pesquisa de Vitimização 2002 e Avaliação do PIAPS. São Paulo, 2002.

JOHNSTON, Lloyd D.; O'MALLEY, Patrick M. BACHMAN, Jerald G. National Survey Results on Drug Use from the Monitoring the Future Study. US Department of Health and Human Services, 1996

KAHN, Túlio. Medindo a criminalidade: um panorama dos principais métodos e projetos existentes. Fórum de Debates: Criminalidade, Violência e Segurança Pública no Brasil. 2000.

KANT DE LIMA, Roberto. A polícia da cidade do Rio de Janeiro, seus dilemas e paradoxos. Forense. 1995.

LEMGRUBER, Julita, MUSUMECI, Leonarda, RAMOS, Sívia. Por que é tão difícil implementar uma política de segurança? Observatório da Cidadania, 2002, p. 46-54.

LIMA, Renato Sérgio de. Contando crimes e criminosos em São Paulo: uma sociologia das estatísticas produzidas e utilizadas entre 1871 e 2000. 205p. Tese de Doutorado - Faculdade de Filosofia, Letras e Ciências Humanas da Universidade de São Paulo, 2005.

LIMA, Renato Sérgio de. Produção da Opacidade: estatísticas criminais e segurança pública no Brasil. Novos Estudos, n. 80, 2008, p. 65-69.

MISSE, Michel. Sobre a acumulação social da violência no Rio de Janeiro. Civitas, v. 8, n. 3, 2008, p. 371-385.
MISSE, Michel. Crime, sujeito e sujeição criminal: aspectos de uma contribuição analítica sobre a categoria "bandido". Lua Nova, n. 79, 2010.

MISSE, Michel. Sujeição criminal. In: LIMA, Renato Sérgio; RATON, José Luiz; AZEVEDO, Rodrigo Ghiringhelli. Crime, Polícia e Justiça no Brasil. São Paulo: Editora Contexto, 2014.

MOSHER, Clayton J); MIETHE, Terance D.; PHILLIPS Dretha M. The Mismeasure of Crime. Sage Publications, 2002.

PAIXÃO, Antônio Luiz. A Organização Policial numa Área Metropolitana. Dados, v. 25, n. 1, 1982, p. 63-85.

OBSERVATÓRIO DE FAVELAS. Caminhada de crianças, adolescentes e jovens na rede do tráfico de drogas no varejo do Rio de Janeiro, 2004-2006, 2006.

RAMOS, Silvia; MUSUMECI, Leonarda. Elemento suspeito: abordagem policial e discriminação na cidade do Rio de Janeiro. Civilização Brasileira, 2004.

RIBEIRO, Ludmila Mendonça Lopes. Nem tudo que reluz é ouro: uma análise da qualidade dos dados do SINESPJC. In: FÓRUM BRASILEIRO DE SEGURANÇA PÚBLICA. $6^{\circ}$ Anuário Brasileiro de Segurança Pública. São Paulo. 2012.

SHERMAN, Lawrence W.; GOTTFREDSON, Denise C.; MCKENZIE, Doris L.; ECK, John; REUTER, Peter; BUSHWAY, Shawn D.. Preventing Crime: what works, what doesn't, and what promising. Washington DC: US Department of Justice, Office of Justice Programs, 1998.

SINHORETTO, Jacqueline et al. A filtragem racial na seleção policial de suspeitos: segurança pública e relações raciais. In: Figueiredo, Isabel Seixas de; Baptista, Gustavo Camilo; Lima, Cristiane do Socorro Loureiro (Org.). Coleção pensando a segurança pública. Braśilia: Secretaria Nacional de Segurança Pública, 2014. 
SHORT, James F; NYE, F. Ivan.Extent of unrecorded juvenile delinquency: tentativeconclusions. Journal of Criminal Law, Criminologyand Political Science, v. 49, n. 4 , 1958, p. 296-302.

THORNBERRY, Terrence P. \& KROHN, Marvin D. The Self-Report Method for Measuring Delinquency and Crime. Criminal Justice, v. 4, n. 1, 2000, p. 33-83.
ZILLI, Luís Felipe; MARINHO, Frederico Couto; SILVA, Bráulio Figueiredo Alves da. Pesquisas de Vitimização. In: Crime, Polícia e Justiça no Brasil. São Paulo: Editora Contexto, 2014.

ZILLI, Luís Felipe; COUTO, Vinícius Assis. Servir e Proteger: determinantes da avaliação pública sobre a qualidade do trabalho das polícias militares no Brasil. Sociedade \& Estado, v. 32, п. 3, 2017, p. 681-700. 



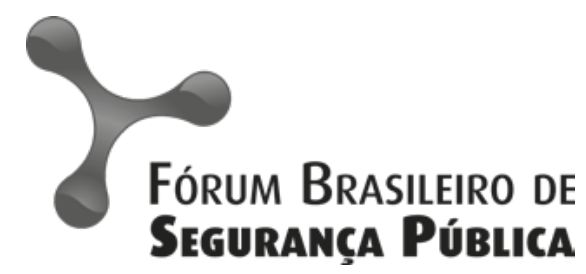

ISSN 1981-1659 